\title{
EXISTENCE RESULTS FOR A NON LINEAR BOUNDARY VALUE PROBLEM ARISING IN KINETIC THEORY OF GAZ IN BOUNDED GEOMETRY
}

\author{
Hicham Maadan ${ }^{1}$ \\ ${ }^{1}$ Faculty of science and technics
}

November 11, 2020

\begin{abstract}
The present paper deals with the existence results on L1 space for a nonlinear transport equation describing the continuous slowing down of electrons in a semiconductor or mettalic medium. Starting with our equation, we transform it in a fixed point problem by a new variant of Krasnosel'skii fixed point theorem for the weak topology involving weakly compact operators on nonreflexive Banach spaces, we give the existence results of the solution
\end{abstract}

\section{Hosted file}

Hicham paper.pdf available at https://authorea.com/users/374834/articles/492267-existenceresults-for-a-non-linear-boundary-value-problem-arising-in-kinetic-theory-of-gaz-inbounded-geometry

\section{Hosted file}

figure.tex available at https://authorea.com/users/374834/articles/492267-existence-resultsfor-a-non-linear-boundary-value-problem-arising-in-kinetic-theory-of-gaz-in-boundedgeometry 